\title{
Ia influencia de las Agencias Internacionales en el proceso de desarrollo de Colombia 1950-1974:*
}

Los últimos 25 años de la historin de los países latinoamericanos se caracterizan por el cmpeño que éstos han puesto en poner en marcha una estrategia cle clesarrollo económico, que con el pasar de los años ha venido complementándose con teorias cle desarrollo social $y$, más recientemente, de desarrollo político.

EI periodo al que actibo cle hacer referencias pertenece a la etapa de la postguerja y con ella a la puesta en maroha del nuevo orden económico internacional que estuvo construido sobre dos pilares [undamentales, a saber: el Fondo Monetario Internacional y el Banco Nundial de Reconstrucción y Fomento; las llamadas instituciones gemelas de Bretton Woods. Estas instituciones vinieron a ser complementadas posteriormente por iBancos regionales, tales como el Banco Interamericano de Desarrollo y por agencias bilaterales de ayuda, tales como la Agencia Internacional para el Desarrollo (AID).

Tria sido tesis favorita de la izquiercla radical la de presentar el proceso de desarrollo de los países de esta parte del mundo como un fenómeno cle depenclencia que, a su tumo, a medida que avanza el proceso, se agudiza aun más.

Sin embargo, a mi entender, son pocas las investigaciones que se than realizado sobre la manera como operan cstos organismos internacionales; sobre la lorma como interactún con los organismos locales; sobre las soluciones de tipo económico o social que plantcan $\gamma$, muclio más importante aún, sokxe aquellas soluciones que excluyen. No sé de estudios que muestren, a nivel de los países la. tinoamericanos, cuál es el impacto clel financiamiento público ex. temo en el desamollo nacional, tomando en cuenta factores tales como la manera como se ve afectado el proceso cle industrialización local por razón de las exigencias relativas a la adquisición de bienes en países extranjeros, nommalmente fuera de la zona; o el impacto que la preparación cle estuclios de base, y lucgo de prefactibiliclad y factibiliclad por misiones extranjeras con muy poca o ninguna participación nacional, ha inciclido en la formación de equi-

- Trabajo basado en una Conferencia dictada en la Universidad de Medellín, 131 de octubre de 1975. 
pos humanos en nuestro medio y en la formación de una tradición investigativa sobre nuestra realidad nacional; cuál ha sido la repercusión que el comportamiento de estats agencias ha teniclo en lo que ha sido $-y$ mucho mús crítico aún- lo que va a ser el proceso de generación de ideas, de escogencia cle opciones, de formulación cle políticas, $y$ de adopción de las mismas; en qué medicla el desarrollo instituciont colombiano, ministerios, institutos descentralizados, departamentos administrativos, fondos especializados, hat siclo incluciclo -cuanclo no directamente influido- por razón cle las necesidades de aclministración cle los préstamos y ell qué forma ese clesarrollo institucional hat afectado tanto nuestro proceso de decisiones como el papel que constitucionalmente le corresponde a determinalas agencias dentro clel listado colombiano. ¿퍼a s.do afectado el papel del Congreso en lo que se refiere a su facultad de ordenar el gasto público?; ien lo que tiene que ver con el proceso ce fiscalización?; ¿en lo que toca a su pappel de colegislador y critico de las politicas gubernamentales? ¿Quién, por ejemplo, ha ejercido uná función contralora mís eficaz, más permanente, más jlustracla en cuanto a las inversiones públicas en el sector eléctrico, en el sector de transporte? ¿El Congreso de Colombia, las Asambleas Departamentales, los Concejos Municipales o el Banco Mundial, el Banco Interamericano, el Fondo Monetario thternacional o la Aid? ¿Quién ha leiclo y quién ha hecho obscrvaciones más cuidadosas a los planes de desarrollo? ¿Estas Agenciats o el Congreso colombiano o nuestros partidos políticos 0 , si se quiere, los grupos de presión locales o la opinión pública o las universiclades? ¿Quién ha sido responsible por la continuidad de algunas politicas, por ejemplo en el sector de exportaciones, en la politica monetaria, en la política de fijar las tarifas de los servicios públicos, en la política de desarrollo eléctrico, etc.? ¿has agencias internacionales o las agencias locales? Toda una serie interminable de preguntas similares a éstas podrían plantearse sin que pudiera, pira responderlas, tener una base cle apoyo en alguna investigación buena o mala que arroje luz sobre estas interrogantes. Ls posible que para muchos no sea necesario ni siquiem interroganse sobre estos asuntos, porque tienen ya suficicnte claridad y si no saben las preguntas, sí, y con toda seguridad, creen que saben las respuestas.

Algunos cliran: si thaty imperialismo, thay clependencia; si thay dependencia, las clecisiones son acloptadas por el país hegemónico, en este caso por los Estaclos Uniclos y el papel cie las instituciones locales no pasa de ser el de simples entidades que sumisamente actúan como entidacles ejecutoras de los designios de la potencia imperial.

Para qué entonces plantear perplejidades, abismarse con interrogantes, reclamar investigaciones y comportarse como si no se supiera 
cual es la realidacl...! Para mí resulta muy interesante examinar la situación desde el punto de vista de los funcionarios que han jugado algún papel en este proceso de cooperación internacional, dicen unos, de dominación dicen atros: ¿Consideran ellos que sus relaciones con los funcionarios colombianos o con las agencias locales, burocríticas o meramente politicas, son tan simples y tan fáciles? ¿El 'Congreso norteamericano, que en varias ocasiones ha adelantado aucliencias sobre lat ayucla norteamericana a estos países y lat ordenado la preparación de informes especiales como el que se preparó sobre Colombia en 1968, no manifiesta ninguna desilusión, ningún desencanto, ninguna frustración, con respecto a las expectativas que se habia forjaclo en cuanto al clesarollo de Colomb:a o de América Latina como resultado del apreciable monto del financiamiento pút.lico externo? El conocimiento que tengo de las actitudes de esos funcionarios y la lectura de diversos informes, unos antiguos y otros recientes, es el de una mezcla de exitos y fracasos, de acuercios $y^{\prime}$ confrontaciones; de acciones, omisiones; de relaciones de confianza $y$ desconfianza; de alianzas eficaces, imposibles y difíciles; de incomprensión; rechazo, fracaso, frialdald y entusiasmo. En lin, la interacción entre estos actores del proceso político no parece ser -como nunca lo ha sido en la viclia politica-, lit cle una relación uniforme, unilineal, estable, invariable, sino, por el contrario, una relación someticla al juego de las personalidades, de las coyunturas, de las urgenciats inescapalbles, que, por supuesto, dan lugar a un tipo de relación mudho mís compleja $-\mathrm{y}$ para mí mucho más interesante- que la simplista de los que ya saben las respuestas a unas interrogantes que todavia no se han planteado.

Cuando el mundo comienza a dir pasos definitivos hacia la creación de un nuevo orden económico internacional $y$, en consecuencia, hacia el establecimiento de nuevals agencias internacionales, resulta un poco uxasnochado, por decir lo menos, pero no por ello menos oportuno, estudiar agencias que parecen hatber cumplido su tarea, como es el caso del Fondo Monetario internacional o el de lal AID, o que estín en trance de perder el papel preponderante que se les asignó para entrar a compartirlo con esi constelación de instituciones ofrecida al Tercer Mundo por el señor Kissinger en su cliscurso del 10 de septiembre ante la asamblea general de las Naciones Unidas. ICon toclo, es ésta una buena ocasión, no sólo tporque estas instituciones se ofrecen más disponibles a dar información, sino porque las conclusiones que se puedan oblener de estos estudios nos van a explicar muchos aspectos cle nuestro reciente pasado $y$, sin duda, muohas lecciones para el trato que en el futuro, de todas maneras, tenclremos con éstas y otras instituciones internacionales. 
Debo, de antemano, disipar cualquier ilusión con respecto a las conclusiones que se puedan deriva de la presentación que voy a hacer en torno a la did, Banco Mundial y orr. Omito lo relacionado con el Fondo Monetario Internacional (tal vez la más poderosa de todas las agencias) porque quizís, por cllo mismo, es la más clada al secreto y por ello la más difícil cle investigar.

Aungue resulta un poco pretencioso cleclararlo asi, es indispensable advertir que estos datos $c$ informaciones, muy simples por cierto, estaín basados en dos investigaciones. La primera de ellas realizada por mí como miemtro de un equipo internacional promovido por al Carnegie Indowment y por el International Legal Center, que descle 1970 hasta 1972 se declicó, en forma csporádica, al analizar el impacto del Banco Mundial, del Fonclo Monetario $y$ la ort en Pakistrín, Turquia, Ghana y Colombia, el cual estudio será próximamente publicado en los Ee.uv. En este equipo preparé el caso de Colombia. ILal segunda investigación es la del profesor Christopher Mitchell de la Un:versidad de Nueva York, quien durante los últimos doce meses adelintó un trabajo de investigación comparatival sobre el impacto de la AID en Colombia y'República Dominicana.

EL FRENTE NACIONAL: UN CONTEXTO

POLATICO APROPIADO

El arreglo institucional que llevó á la creación del sistema del Frente Nacional, aunque no tuvo influencias externas en cuanto a su origen $y$ a su concepción, se constituyó en un excelente marco, muy apropiaclo para la operación de las agencias internacionales. El Frente Nacional tuvo, entre otros efectos, el de despolitizar la estructura gubernamental. La clistribución equitativa clel poder entre los partidos traclicionales, al margen de los resultados eleatomales, hizo que el conflicto político, por lo menos dentro de los parámetros tradicionales, resultara menos significativo. De esta manera cl proceso de moclernización entre nosotros adquirió un estilo más tecnocrático. El Banco Munclial, el Fondo Monetar:o, el Banco Interamericano, la Agencia internacional de Desarrollo y la orT encontraron en este marco institucional un buen escenario parn ejercer su influencia, que en la mayoria de los casos ellos conciben como apolitica, como puramente técnica. Tal ve\% sin que nadic se lo hubiera propuesto, el estilo de las agenciats internacionales y el estilo de los gobiernos del Firente Nacional winieron a reforzarse mutuamente y a crear una tácitat alianza de tipo tecnocrálico, que es responsable por un apreciable repertorio de políticas y programas $y$, por qué no decirlo, responsable también por graves omisiones.

Al establecer las cameterístions de esta tendencia, estoy solamente 
señalindo las posibilidades y oportunidades para los actores políticos que sabian moverse clentro de este mundo supuestamente escéptico de la tecnocracia sino que, al mismo tiempo, estoy llamando Ia atención sobre las eventuales dificultades y obstáculos que estas agencias podrian encontrar si hicieran uso de canales más polít:cos y ventilaran sus programas y acciones en los foros locales controlados por la clase politica.

A medicla que el investigador acitdémico examina la naturaleza de los programas, sectores y politicas que tienen que ver con las diferentes agencias internacionales, le resulta fácil darse cuenta de que una institución como el Fondo Monetario Internacional, que tiene que vérselas con aspectos de la política económica a nivel macro, como son la política monetaria, la política de intereses, la política crediticia, la politica salarial, los problemas de balanza de pagos y de fijación de la tasa de intercambio, cstá más expuesta a la crítica de la opinión pública, a esporádicos debates parlamentarios e, inclusive, a confrontaciones serias con las máximas autoriclades del Estado. Para qué recordar la crítica de que ha sido objeto el Fondo Monetario entre nosotros, las reservas que hemos tenido sobre la ortodoxia de su politica, la resistencia que con éxito en una ocasión $y$ 'sin éxito en otras muchas, hemos ofrecido a sus recomenclaciones en cuanto a exigir a veces, sin consideración al momento político, clevaluaciones y otras políticas, que difícilmente se pueden escapar a la atención y decisión de las más altas autoridades. No creo que se recuerde el ejemplo de una confrontación pública entre el gobierno colombiano y el Banco Mundial o la our o la AID que tenga las características de la que en los primeros meses del gobierno del pres:dente Lleras sostuvimos con el Fondo Monctario Internaciona1, $y^{\prime}$ de rebote, es cierto, con el prool o cartel de agencias internacionales.

En que las confrontaciones con el Fondo Monetario Internacional en tColombia o en Inglaterra. o en el Uruguay por la naturaleza ineludiblemente política de sus recomendaciones, hace muy dificil que esta agencia, no obstante su cliscreción, su ningún apetito pu. blicitario, y sus sutiles y casi secretos manejos, pueda escaparse en alguna forma, así sea remota, de algún control por parte de la opinión pública.

La naturaleza de las políticas en que está interesada la ort (política laboral, política de formación profesional, política cle seguridad social) no han alcanzado entre nosotros un nivel de politización ni siquiera mínimo; las politicas del Banco Mrundial en materia de desarrollo eléctrico, transporte, desarrollo portuario y ahora en el campo del desarrollo sural, salud, desarrollo urbano y turismo, no han sido tampoco objeto de mayor debate nacional; las políticas 
del Banco Interamericano de Desarrollo en materia de desarrollo universitario o de electrificación rural clieron (sobre todo la primera cle ellas) lugar a cierta agitación estudiantil a lo largo de este continente, pero paradójioamente no impidieron. que el principalisimo propuisor de ellas, el señor Felipe Herrera, fuera el candidato de la izquierda unida en Chile para la Rectoria de la Universidad de Chile clurante el régimen de tAllende; tumpoco dan lugar a un juego político los programas de la Ans en materia de educación primaria y secundaria o en lo que toca al desarrollo de las ciudades intermedias, etc.

En sintesis, to que qu:ero clecir es que el enloque sectorial y especifico ligado a políticas concretas, le permite a las agencias internacionales ejercer una influencia mayor dentro de nuestro sistema político.

Debo añadir que cuando una agencia internacional promueve políticas globales, se expone a mayores fr.cciones y conflictos con los poderes centrales.

Hay otro factor que aumenta la capacidad cle influencia de estas agencias entre nosotros y cstá clado por el alto grado de comunicacrón e información entre ellas; por la coordinación y distribución de funciones y por el comportamiento a manera de pool que caracteriza su acción. Esto se hizo evidente en el conflicto entre el gobierno cle Carlos Lieras y el Fonclo Monetario Internacional, en el cual se vio que un desacuerclo con el Fondo Monetario Internacional implicaba un desacuerdo con todas las agencias $y$, por ello mismo, una suspensión simultánea de desembolsos y de negociaciones. Asi lo denunció el presidente Lleras Restrepo en su momento y así lo describo en un estudio del caso que hice sobre esa interesantísima confrontación, la cual, por otra parte, ha sido analizada por Teresa Hayter y por Richard Maullin.

Otros factores que aumentan las potencialidades de influencia de estas agencias, son: el excelente conocimiento que tienen sobre el país y sus mecanismos clecisorios; y el grado de estabilidad y permanencia cle los funcionarios internacionales que tienen que tratar con la inestable y pasajera burocracia colombiana.

Una buena ilustración de la capaciclacl de coordinación de las agencias internacionales se encuentra en el estudio de casos 'que doña Eilen O. Schwartz, miembro del Comité de Relaciones Exteriores del Senado cle los Estados Unidos, preparó a solicitud del subcomité para los Asuntos de las Repúblicas Americanas, y que ticne fecha $1^{\circ}$ de febrero de 1969. Dice así:

"The State Departament suggested the following division of effort. The United States would concentrate its assistance in the fields 
of agriculture, industry, housing, and improved tax administration, with some limited supporting attention to education and public thealth. The IBRD would concentrate its attention in its traditional fields of specialization, namely, power and transportation. The Inter-American Development Bank (IDB) would give preferential atention to water and sewerage systems. The oAs would provide technical assistance and modest financial ihelp in the field of development planing and taxation. Finally, the participants from the Development Assistance Committee (DAC) would give primary attention to specific projects and specific industries in which the individual countries had special interests". (P'ígina 69).

Otr"a indicación interesante sobre la ventaja que para una agencia trae la estrategia sectorial frente a la estrategia global, es la que escribe el señor William C. Rhodas, en su trabajo "Sector Lending: in Colombia" (paper, ArD/Bogatá, November 21, 1969), en el cual ofrece explicaciones muy interesantes para justificar, en estos términos, el cambio de los llamados préstamos de programa cuya eficacia en términos del potencial de influencias de la AID se había debilitado, a la estrategia de préstamos sectoriales a partir de 1968, los cuales incrementaban esa influencia. Esto es lo que trata de describir el profesor 'Christopher Mitohell de la Universidad de New York, en su estudio titulado "ILa $\wedge \amalg$ y las alianzas políticas en CoIombia y la República Dominicana (pág. 3)".

Finalmente debo mencionar la tendencia, cada rez más marcada, cle las agencias internacionales, dirigida a negociar los préstamos con las agencias directamente interesadas y con los funcionarios cuya mayor o menor fortuna en su gestión administrativa está ligada a la consecución y ejecución de los préstamos. Esta fue una tendencia que en su momento el presidente Lieras Restrepo detectó apropiadamente y prohibió a través de decretos muy explícitos en esta materia. Con todo, no siempre es suficiente la medida mera. mente legislativa y en ocasiones ciertos usos y prácticas logran perpetuarse e ir más allá del marco de la propia ley y una y otra ve\% se hace inclispensable la vigilancia alerta de las autoridades centrales para evitar esta alianza fácil entre partes interesaclas solamente en políticas específicas, al margen de su significado e impacto a nivel global.

Con frecuencia nos preguntamos en qué momento y cómo fue que ello ocurrió: el Estado colombiano se despedazó en mil instituciones; los ministerios se convirtieron en agencias tradicionales, sin recursos, sin funcionarios, sin elementos; ¿a qué se debió que las administraciones seccionalos y municipales no superaran los defectos propios de una herencia colonial tremendamente limitadora 
y junto a ellas proliferan empresas descentralizadas e institutos que se movian con actividad y eficacia y dejaban a los Concejos Municipales, a las Asambileas Departamentales, $y$ en general, a las entidades políticas, sin un papel eficaz que cumplir? Una de las principales conclusiones de mi estadio sobre la acción del Banco Mrunclial en Colombia, es precisamente, la de que ha sido politica de esta institución, condicionar los préstamos a un proceso de modernización institucional sectorial. O sea que el Banco Mundial en su afán de asegurar el éxito del proyecto, se desentendia de lo que pudiera ocurrir a otros niveles, no importa qué tan estratégicos, de la administración pública, y se concentraba en hacer exigencias de racionalidad y eficiencia administrativa, muchas veces ni siquiera a nivel de una agencia autónoma sino de una oficina a nivel de un ministerio, por ejemplo.

Es por ello que el clesarrollo del Valle del Cauca está ligado a la creación de la cro como una entidad apolitica, según lo clice la misma ley de su creación, que el desarrollo del sector eléctrico está ligado a unas instituciones muy técnicas, muy modernas, muy eficaces seguramente y muy al margen cle preocupaciones políticas respetables $y$ legítimas, tal es el caso del Instituto Colombiano de Electrificación, Chidral, cro e Interconexión Eléatrica S. A. ¿Y qué consideración legitima política se podría mencionar si Colombia exhibe hoy un desarrclio energetico impresionante? IPues seguramente muchas; pero se me ocurre mencionar una muy importante para mí, cual es la del enorme desequilibrio que existe clescle el punto de vista regional, en la distribución del poder eléctrico. Es el olvido de los sectores rurales, de la región de la costa y de otras zonas geográficas del país, en favor del fortalecimiento del triángulo geográfico Valle-Antioquia-Cundinamarca, con todas las secuelas que este desequilibrio trae en términos de industrialización, politica de inversiones, creación de empleo, etc. Desequilibrio que este gobierno, hay que reconocerlo, está remediando.

Es así como se explica que para fomentar el esquema de educación vocacional a nivel del bachillerato (que es la tarea cle.los INEAM, hubiera siclo necesario crear una agencia especializada bajo el nombre de Instituto Colombiano de Construcciones Escolares. Y que para mancjar el préstamo para la construcción del programa de la zona oriental en Bogotá, hubicra sido necesario establecer el P1Duzor - para canalizar los créditos blandos hacia el sector privado, fuera necesario crear el Fondo de Inversiones Privadas del Banco de la República, o del Fondo Financiero de Desarrollo Urbano para administrar los dineros del préstamo de la AID para las ciudades intermedias.

Por aso no es de extrañar que el presidente del Banco Mundial,

$$
\left[\begin{array}{ll}
6 & 4
\end{array}\right]
$$


señor George D. Woods, le escribiera al presidente de Colombia en 1963 en los siguientes términos: Colombia ha organizado muohas instituciones públicas autónomas eficientes $y^{\prime}$ el gobierno ha permiticlo que ellas funcionen sobre una base estrictamente técnica. La existencia de estas instituciones facilitará mucho la ejecución de los programas. Es importante que esta libertad para operar como organizaciones estrictamente técnicas, sea mantenida. (Enero 25 de 1963).

No sorprencle que de los préstamos otorgados ipor el Banco Mundial durante el periodo 1949-1972, 36 de ellos hubieran sido hechos a institutos descentralizados y solamente 15 directamente al gobierno central. Una tendencia similar se nota al examinar la lista de proyectos que ha sido presentada a cinco grupos de consulta: en el período 1962-1971. De 40 proyectos solamente 4 correspondian al gobierno centual.

Examinemos más de cerca las motivaciones, concretamente las del Banco Mundial, para incrementar esta política de canalizar sus recursos hacia las agencias descentralizadas y no hacia el gobierno central:

19 Asegurar el control directo en la ejecución del préstamo.

29 Asegurar sistemas independientes de contabilidad y auditoria.

3? Establecer políticas de compras o adquisiciones que no estén referidas a las exigencias locales sobre esta materia.

40 Escapar la interferencia política y otros inconvenientes de tipo doméstico. (La crítica de los cuerpos legislativos, el control de los mismos, los sistemas de reclutamiento de personal de acuerdo con el servicio civil, el control presupuestal, etc.).

Permitanme, así sea al precio de insistir sobre aspectos ya mencionados, señalar algunas de las consecuencias politicas que para Colombia ha tenido esta estrategia del Banco Mundial.

Por muy sabida, no thago nueva referencia a la consecuencia de dimensiones macro-políticas que tiene que ver con el complejo fenómeno de la dependencia, pero si voy a indicar cuáles son las consecuencias más específicas a nivel del funcionamiento interno de nuestro sistema político.

En primer iugar, se desarrollan aquellos sectores para los cuales el Banco Mundial ha asignado preferentemente recursos financieros. $Y$ se compromete alli, no solamente la capacidad de endeudamiento de Colombia, sino las partidas presupuestales que resulten necesarias a titulo de contrapartidas. Se tornan modernas, fuertes y eficaces entre nosotros, las agencias que están referidas a los sectores 
que resultan prioritarios dentro de la filosolía de desarrollo económico que tiene el Banco.

Uno puede preguntarse por qué un sector como el de la administración de justicia, por ejemplo, en un país donde los abogados ejercen tanta influencia, constituyen la mayoría clel Congreso, buena parte de la clase política y es la profesión de nuestros últimos tres presidentes, ' $y$ ' de la mayoria de los ministros, ¿cómo es posible que ese sector jcientificado como uno de los funclimentales cle la acción. del Estado, se mantenga como una de las ramas del poder público más tradicionales en el senticlo peyorativo de la expresión, más escasa de elementos, mís atrasada en sus metoclologías, en sus proccdrmientos de trabajo, más desincronizada de las necesidades $y^{\prime}$ demandas que le formula una sociedad en acelerado crecimiento y con problemas de impunidad cada día mayores?

¿Es que acaso los colombianos no hemos estado conscientes de ese problema clurante los últimos quince años? is que carccemos de un suficiente número de abogados o de facultacles de clerecho que puedan interesarse en el problema? ¿lis que los ministros cle justicia than sido incompetentes? illes que el problema no nos atos gat hasta la desesperación? Pala mí la respuesta es bien fácil: Frasta la fecha ninguna agencia internacional se ha interesado por el desarrollo del sector de la justicia, por su modernización, por su eficacia. $Y^{\prime}$ que la solución de muchos problemas colombianos no está ligada a la conciencia que sobre ellos tengamos, a la urgencia que les asignemos, a la desesperación y angustia que nos produzcan, sino a las prioridades que las agencias le fijan a los problemas del desarrollo $\mathrm{y} a$ los recursos que consiguientemente ellas asignan. El sector de la justicia, no importal qué tan vital resulte para nosotros, no es una prioridad de ninguna de laş agencias internacionales y por ello ese sector ha permaneciclo inerme, empobreciclo, sin prestigio, despreciado, casi abandonado; no importa que toclos los clías cligamos retóricamente $y$ :sinccramente, además, que ése es un problema vital para 'Colombia. Los recursos del país están comprometiclos y no hay manera de canalizar hacia ese sector las ingentes partidas presupuestales que la atención adecuada del mismo requiere. Yo creo que en esto es. mucho mayor: nuestra responsabilidad que la de las agencjas internacionales $\mathrm{y}$ aclaro que cuando hablo con algo de ira sobre esta situación, no trato de eludir la responsábilidacl de nuestra clase dirigente y de nosotras mismos en cuanto a este probiema ni mucho menos de trasladar - lo cual scria muy cómodo- semcjante deber a las agencias internacionales.. Lo digo por. via de ejemplo, por la actualidad dẹl problema y porque así lo consigné en el estudio de caso a que tantas veces he hecho referencia.

- Podría mencionar otro sẹctor, oța rama del poder público, qüe 
por obvias razones (no tengo para qué abundar en ellas), se ha quedado también en términos de prestigio, eficacia, utilización de técnicas apropiadas, al margen del proceso de modernización y cada día más limitado para cumplir con eus funciones legisladoras y físcalizadoras, como es la rama legislativa a nivel nacional, departamental y' municipal.

Espero thaber clarificado que para una agencia internacional la sola disposición de recursos financieros y su estrategia de desembolsos paulatinos no es suficiente para ejercer la palanca debida dentro de un sistema politico. Se requiere de alianzas, exclusiones, cliscreción, adopción de una estrategia en favor o en perjuicio de otra, etc., para que la acción pueda resultar eficaz, por lo menos en términos de la agencia. Y no he querido implicar que la acción de cstas agencias internacionales sea invencible $y$ que definitivamente el país sucumbe fatalmente ante ellas. Precisamente me interesa destacar aquellos aspectos y aquellas situaciones que le dan a nuestra. burocracia local una capacidad de decisión mayor, una posibilidad de influir en las políticas, más acorde con las necesidades nacionales. Por ello $\mathrm{mi}$ insistencia en subrayar bien sea las oportunidades en las cuales se produjo el conflicto y el gojbierno colombiano sacó adelante sus puntos de vista, o bien atquellas en las cuales las agencias internacionales se vieron obligadas a buscar estrategias que hicieran más fácil la promoción de sus propios esquemas.

Hay otras consecuencias políticas que no quisiera pasar por alto. En la medida en que los criterios técnicos se hacen cada vez más importantes, adquiere mayor relevancia el proceso de planeación sectorial o global $y$ thay menos oportunidad o necesidad de obtener un firme apoyo popular para determinadas politicas. De esta manera, la iniciativa política a nivel popular y la respuesta a esta iniciativa, se hace cada dia menos y menos relevante en el proceso de formular politicas públicas. Es por ello, como ya lo dije, que las consideraciones de tipo regional se convierten en barreras para la eficiencia. Is por ello, también, que n'uestra clase politica está cada dia más aislada del proceso treal de decisiones y se ve obligada a realizar sus campañas políticas sobre la base de planteamientos muy generales y muy vagos y mury pocas veces sobre el conocimiento de las realizaciones gubernamentales pasadas $y$ recientes. No es de extrañar; entonces, que entre nosotros el proceso electoral se haga cadit vez más azaroso y nos produzca, resultados tan sorprendentes como el del 19 de abril de 1970 .

De esta manera, la tecnocracia y el aislamiento de ciertas agencias con respecto al proceso político, se hace cadá día más de moda y se las reviste de todos los símbolos de la racionalidad, la imparcialidad; la ..eficiencia y hasta el bien común. 
Es bien sabido que la Onganización Internacional del Trabajo, organismo que sobrevivió a la extinguida Liga de las Naciones, surgió como la respuesta occidental para contrarrestar el fantasma que, según el Manifiesto Comunista, recorría el mundo. Su filosofía reformista, pero esencialmente gradualista, estaba construida sobre una base pluralista y por ello en el gobierno mismo de la ort, aşí como en los organismos que ella promueve en el mundo, thay una distribución tripartita del poder entre el gobierno, los propietarios del capital y los trabajadores. Analizar ia orr resulta particularmente atractivo porque ésta es una organización con un tremendo potencial ideológico y programático, pero prácticamente carente de la palanca que da el disponer de recursos financieros para apoyar las ideas y los programas que se propone. Con todo, es fácil comprobar que su impacto es muy grande y' que, en general, no obstante la precariedad de sus recursos económicos, sus métodos $y$ estrategias de penetración son bastante eficaces.

Hagamos un brevísimo repaso de lo que ha sido su acción entre nosotros. Las instituciones más importantes de lo que podríamos llamar el sector social dentro del Estado colombiano, han estado intimamente ligadas en su concepción y en su funcionamiento, en sus éxitos y fracasos, a la acción e icleología de la ort. El propio Ministerio de Trabajo y Seguridad Social, las hasta ahora principales agencias autónomas adscritas a ese Ministerio, el Instituto Colombiano de Seguros Sociales, el Servicio Nacional de Aprendizaje, así como el Consejo Nacional del Trabajo y el Consejo Nacional de Salarios, los dos principales cuerpos consultivos del Ministerio, son todos desarrollos institucionales que en uno u otro momento, en mayor o menor grado, están vinculados a las actividades de la oir $y$ a sus orientaciones. $\mathbb{E}$ I SENA, sin duda, constituye la realización más importante. La propia orT preparó recientemente un informe para el gobierno colombiano, en el cual recogió los logros del SENA durante esta década. Allí se afirma que sin la colaboración de la oIt $-\mathrm{y}$ ello es absolutamente cierto- Colombia no habría sido capaz de obtener los mismos resultaclos en el campo de la formación profesional.

La colaboración de la or' en este campo se remonta a 1956 cuando el gobierno solicitó asistencia técnica en la preparación de estadísticas sobre la oferta de mano de obra calificada. $\mathbb{E} 1$ SENA del Brasil facilitó los servicios del experto Salas Da Silva, quien a solicitud y con el patrocinio de la ort, prestó su concurso. Se considera que la contribución de Da Silva fue decisiva en la creación del SENA como un instituto descentralizado, por medio del decreto No 118 del 21 de julio de 1975 , y el decreto 164 del 6 de agosto del mismo 
año. El SENA es un ejemplo de una acción administrativa basada en un cuidadoso proceso de planeación. Durante cuatro años, 18581962, con la ayuda de la orT, se hizo un amplio trabajo en torno a las necesidades de mano de obra, entrenamiento de instructores, construcción de centros, adquisición de equipo y búsqueda de cooperación internacional. Cumplida esta etapa, se inició un intenso trabajo. Y hoy el SENA exporta su capacidad y su conocimiento. Es un caso de máxima utilización de nuestros recursos con el soporte técnico de una institución internacional. Lo cual no quiere decir que no se han presentado fallas, que no se han cometido tremendos errores y que no haya thabido desperdicio de recursos. Pero dentro del contexto colombiano es un ejemplo casi inusitado de racionanalidad, dedicación, profesionalismo, eficiencia y, por qué no decirlo, de éxito.

Seria muy largo mencionar las contribuciones de la orr a través de sur sistema de convenciones al desarrollo de nuestra legislación laboral e, inclusive, de la legislación en cuanto se refiere a los campesinos y a los indígenas. Otra cosa es que el nominalismo tque caracteriza a una parte de nuestras instituciones legales, le haya quitado eficacia a esta acción. Cosa semejante se puede afirmar con respecto a la reestructuración del Ministerio del Trabajo en virtud de los Decretos 3134 y 31136 de 1968 , los cuales fueron diseñados bajo la guia del experto de la ort, Giovanni Di Polo.

Muy diferente es la situación del Instituto Colombiano de Seguros Sociales, que no ha sido capaz de construir una eficaz maquinaria administrativa, ni un sistema financiero sensato y que no ha sidlo capaz, en casi treinta años de existencia, de ofrecer protección a una parte sustancial de nuestra población.

La eficacia de la ort está dacla por sus acciones a través de agencias especificas en campos limitados. Hay un intento, por parte de la ort, de influir a nivel macro-económico y macro-social y tal es el caso de la Misión Sears, que tuvo por objeto presentar un informe sobre la estrategia de creación de empleo en Colombia, que finalmente no fue otra cosa que un plan de desarrollo a nivel nacional. Acogido con entusiasmo inicialmente por el propio gobierno saliente, el del Dr. Carlos iLleras, por el gobierno que acababa de iniciarse, el del Dr. Pastrana Borrero y en general por la opinión pública, incorporado dentro del plan trienal de desarrollo presentado por la administración Pastrana al Congreso en 1970, sufrió muy pronto los embates de las centrales sindicales, de algunos parlamentarios y en el transcurso de un año, luego de haber demostrado su eficacia para la retórica oficial, sucumbió. El programa de las cuatro estrategias inspiradas por el profesor Currie, director de la primera misión del Banco Mundial, en 1949, lo sustituyó plenamente. Es el gran fracaso de la olT entre nosotros, pese a que en algún momento 
sus esquemas tuvieron acogida, no solamente a mivel doméstico, sino a nivel de otras agencias internacionales muy influyentes en Colombia. Este es otro caso de fracaso de una agencia internacional al tratar de promover programas ique, por su envergadura y su contenido, no pueden escaparse al proceso político colombiano y que por ello sufren los altibajos propios de nuestra dinámica política.

Examinemos ahora el caso de la AID, a la cual, por otra parte, ya he hedho objligada referencia. Neamos cuáles son algunas de sus peculiaridades, de sus éxitos y fracasos.

En primer lugar conviene recordar que la Airo obra como una agencia bilateral de cooperación, en contraste con el carácter multilateral del Banco Mundial, del Fondo Monetario, del Banco Interamericano y de la ort. No quiero insinuar con esto que estas últimas agencias carecen de influencia decisiva por parte del gobierno norteamericano. Este controla Ia AiD, Ia cual entra muchas veces en conflicto con el propio Congreso norteamericano, con cl Departamento de Comercio, con el Departamento de Agricultura, etc. En las otras agencias multinacionales la posición norteamericana es predominante y en la or hay que reconocer an predominio, por lo menos ideológico, de los ingleses.

La AID es la respuesta que, en nombre de la Alianza para el Progreso, dieron los Estados Unidos a la revolución cubana: Bu acción se enmarca dentro de la estrategia, ya superada, de la guerra fría. Se proponía, ante todo, una estrategia de rápido crecimiento económico y de desarrollo democrático. El objetivo propiamente político era bien explícito, aunque las estrategias para alcanzarlo, como era natural, siempre fueron objeto (ya lo veremos) de muy encontradas y dispares opiniones. No parece que hubiera oourrido cosa similar con las estrategias de crecimiento económico.

La extensión de esta conferencia no me permite entrar en detalle en las operaciones de la aid entre nosotros $y$ por ello me limito a recordar los objetivos que los gobiernos latinoamericanos se comprometieron a realizar como resultado de un esfuerzo cooperativo con los Estados Uniclos en la Carta de Punta del Este en 1961: Obtener un crecimiento sostenido del ingreso per cápita y crecimiento económico autosostenido no inferior al $2,5 \%$ per cápita anualmente.

Lograr una distribución más equitativa del ingreso naciona] y dedicar una proporción más alta del producto nacional a la inversión, manteniendo al mismo tiempo una politica estable de precios.

Lograr la diversificación económica para reducir la dependencia de las exportaciones de productos primarios y estabilizar los ingresos por razón de las exportaciones.

Aumentar la productividad agrícola y estimular, al mismo tiempo, procesos de reforma agraria. 
Eliminar el analfabetismo de los adultos y asegurar parà 1970 el acceso de todos los niños en edad escolar, por lo menos a seis años de educación primaria.

Mejorar las condiciones de salud, incluyendo un aumento a la expectativa de vida de por lo menos cinco años.

Incrementar la construcción de viviendia barata.

Fortalecer los acuerdos existentes sobre integración económica.,

$Y$ todo ello unido al compromiso de modernizar las estructuras tributarias, a mantener políticas monetarias $y$, fiscales sensatas, a reducir el desempleo y a estimular la inversión privada:

Mril doscientos tres millones de dólares (US\$ 1.203.3) recibió Colombia en el período 1962-1973 para implementar estas politicas. EI informe de la doctora Schwartz para el iCongreso americano recoge hasta febrero de 1969 los éxitos y los tracasos de la Afid en Colombia. Ellos están concatenados con las políticas promoviclas por las otras agencias internacionales y que a partir de la constitución del Grupo de Consulta en 1963 than sido objeto de una eficaz coordinación por parte del lider de ese grupo, el Banco Mundial.

Según el mismo informe "la asistencia externa norteamericana 'Iogró on Colombia su objetivo político básico, pero se quedó corta en los objetivos económicos y sociales de la Cara de Punta del Este. Desde el primer préstamo del programa, en aibril de 1962, un objetó primordial fue, dice el informe tantas veces citado, la estabilidad política y el mantenimiento de las instifuciones politicas democräticas de Colombia a través dẹl äpoyo a los súcesiyos gobiemos dél Frente Nacionajl. Esto ha sido logrado".

Es más, el informe añąle que el éraluadọ del programa de ayuda norteamericana a Colombia deberịa tomär en considenación un factor imponderable como es el de "zqué le habría pasado ạl próceso pólítico en Colombia si no hubiera thabido un programa de ayuda o' si a ćsta se hubieran atado condiciones diferentes' o más rigúrosas?". Y más adelante añade: "El programa de ayuda en Kolonibia ha comprado tiempo para que las instituciones políticas colombianas preparen Ios cambios que cualquier persona, en una posición de responsabilidad en cualquier pais, sabe que deben producirse. Pero las colombianos han usaclo este tiempo a su antojo. La pre. 'gunta qué este estudio plantea; pero que no puede 'responder es: ¿Se habrían movido los colombianos más rápidamente si hubieran ténido menos tiempo, o las presiones thabrían sido tan grandes que la estructura total del país haibrif́t entrado en colapso hacia la anarquía o la dictadura?

Paradójicamente, y asi lo demuestra el estudio de John . Richard Davidson sobre la implementación de los objetivos de desarrollo político de la Alianza para el Progreso, la AID en Colombia fue muy reacia a poner en marcha las estrategias sugeridas por el grupo de 
congresistas norteamericanos liberales dirigidas a crear una presión, desde la base popular, que acelerara el proceso de reformas en: la América Latina. Esta fue la famosa reforma introducida a la ley de asistencia externa latinoamericana en el llamado titulo noveno. No voy a describir en detalle el contenido de esta estrategia explicita de desarrollo politico, ni voy a presentar los ejemplos de los paises en donde ella fue implementada más sistemáticamente como Costa Rica o donde tuwo aplicación limitada como Perú, Chile, Guatemala. Baste decir que analistas como Levinson, de Onis, Liewen, Ferguson, Packenham, Davidson, estiman que "muy poco se ha logrado o intentado en el área de influir conscientemente el desarrollo políticô de América Latina, to cual se debe a la percepción de que la habilidad de los Estados Unidos para influir este proceso es más bien marginal. (Davidson, página 4).

Los burócratas de la AiD, según Davidson, veían con recelo $y$ sospecha una estrategia clara y directa de desarrollo político ai corto o a largo plazo, porque, entre otras cosas, ponía en peligro su imagen de tecnócratás politicos qque nada tenian que ver con el proceso político.

'Observémos, para concluir, que esta estrategia directa de desarrollo político concebido como la movilización de los sectores bajos a través de nuevos mecanismos de participación organizada, fracasó no sólo por lo que queda atrás dicho, o sea porque la influencia política directa de los Estados Unidos era marginal, sino porque, finaImente, cualquier influencia tenía que ceder ante la necesidad más urgente de salvar el sistema político existente. Asi fue como la ay'uda atada, condicionada a las reformas sociales, siempre admitió postergaciones ante la inminencia real o no de descalabros de tipo institucional. $Y$ hay tque añadir que la desaparición del mito de la inminente revolución debilitó de parte y parte la necesidad de implementar reformas y de estimularlas a través de estrategias de desarrollo político en la base popular.

Es que, finalmente, no era tan cierto que América Latina estaba "a un minuto de la medianoche". Todo parece indicar que fueron más eficaces los latinoamericanos en explotar el miedo norteamericano a otra Cuba que los norteamericanos en: explotar el miedo de los gobiernos locales establecidos frente a una eventual insurgencia popular.

\section{CONCLUSION}

Al analizar el papel de las agencias internacionales en Colombia, no the pretendido insinuar que ellas son organizaciones primordialmente políticas ni he pretendido implicar que ellas tienen objetivos escondidos o finalidades indignas. He querido destacar que, no obs- 
tante su enfoque sectorial a través de agencias específicas, sus acciones tienen unas consecuencias políticas inescapables que me parece, ellas y nosotros, debemos entender claramente.

En este sentido el aislamiento dentro del cual se tha buscado mantener, por parte de los funcionarios internacionales y de los funcionarios colombianos, la operación de estas agencias con respecto al mundo de la política colombiana, merece ser reexaminado y reformulado. El papel de esta élite transnacional tán iclentificada en sus concepciones $y$ valores, compuesta de funcionarios internacionales, ingleses, holandeses, ihindúes, latinoamericanos, colombianos, etc., debe, de alguna manera, someterse al circuito normal de decisiones en Colombia, sin que por ello m:smo sufra la seriedad en el diseño de las políticas y la responsabilidad en su ejecución. Este fue un aprendizaje que bien habriamos podido practicar durante ese periodo ideal, ya superado, del Frente Nacional. Reconozco que hacia el futuro puede resultar mucho más difícil, arriesgado y complejo, som meter estos proyectos de operaciones a nuestro circuito normal de decisiones.

No me sorprendería que muchos se extrañen de que no hubiera hecho girar con más énfasis estas reflexiones en torno al tan llevado $y$ traído tema de la dependencia; oue no hubiera convocado en mi auxilio a Cardozo, a Faletto, o Frank y a todos los que se han hecho famosos con el análisis de ese concepto. Pero es que aunque no desconozco la naturaleza del fenómeno y su vigencia entre nosotros, tengo la idea -y hasta la ilusión- de que se hace cada día más importante y más necesario que entendamos este fenómeno como uno de doble vía. Que no lo concibamos como una relación fatal, insuperable, incontrolable, ni tampoco como una situación que puede romperse al golpes de audacia, de algarabía o con unos cuantos slogans. En una forma menos abstracta, formularía así el problema: $\mathrm{Ni}$ ahora ni en el futuro seremos capaces de tomarnos todo el café que producimos. En alguna forma el mundo desarrollado, la constelación de países ricos e industrializados, dependen del Tercer Mundo, de los paises pobres, de los paises que llamamos dependientes. $O$ sea que en alguna forma, seguramente unos más que otros, somos dependientes. La lección que nos va a dejar la década de los años 70 , es la de que los países que tal vez fueron más sumisos, más explotados, más dependientes, de la noche a la mañana, porque miraron el fenómeno de la dependencia como uno de doble vía, pusieron en tela de juicio el orden económico internacional establecido desde la segunda guerra mundial y pasaron a convertirse, si no en Ios amos del mundo, si en actores y protagonistas respetables del sistema político intennacional.

Me preocupa más tener claridad sobre aquellos factores que hacen interdependientes a los diferentes países $y$ continentes, dilucidar la 
dimensión de la dependencia de los paises inclustrializados con respecto a las materias primas, a los alimentos, al trabajo, a las oportunidades de comercio internacional, al control del medio ambiente, que ofrecen los paises pöbres, que agitarme y paralizarme con el fatalismo de una situación que no admite sino soluciones radicales. A lo largo de esta presentación, the tratado de señalar cómo en ocasiones los factores de poder doméstico o nuestra indisciplina, o nuestra ineficacia, o si se quiere, nuestra malicia y viveza, ihan servido de límites a la acción y a las pretensiones de las agencias internacionales. Eso es todo lo que he querido decir: Que éste es, como todos los sistemas políticos del mundo, un sistema penetrable por actores políticos externos, pero que la acción de ellos encuentra barreras, no es definitivamente fácil; que, en una palabra, tiene limites. Insisto: en que tratado y planteado hasta el cansancio y la fatiga el tema de la dependencia entendida como un fenómeno en el cual nosotros jugamos el papel de los explotados, de los inermes, de los incapaces, comencemos a dirigir muestras preocupaciones intelectuales y nuestras acciones hacia el otro aspecto de este fenómeno que, indudablemente, tiene dos caras, para ver cuáles son las potenciáliclades que como nación tenemos a la vista y cuáles los aliados que podamos encontrar en países semejantes al nuestro, y en sectores que simpatizan interesadamente o no, con nuestras posiciones dentro de los países ricos e industrializados. Esta es una actitud muy coherente con la actual coyuntura politica internacional que aparece muy fluida, muy plástica y mercurial.

No quisier que estos planteamientos me colocaran como un enemigo de la ayuda internacional o de la cooperación internacional, como se quiera llamarla. Una y otra vez, en la cátedra: y en conferencias, he sostenido que el ingreso que hay que redistribuir no es el que se encuentra dentro de los límites de la geografía colombiana, porque ni aqui está todo el ingreso nacional, ni todo el ingreso que está a'quí nos pertenece. Mucho más apropiado, jugar con el concepto de la justicia económica internacional, con el concepto del ingreso mundial del producto bruto mundial y de la necesidad de redistribuirlo equitativamente, sin referencia a fronteras geográficas que, por otra parte, no existen cuando se trata de hacer utilidades o de poner a funcionar las empresas transnacionales.

A mí me parece que la ayuda intemacional o la cooperación no constituyen una dádiva ni una expresión de la filantropía internacional. Creo que esos dineros nos pertenecen, no de ahora, sino desde hace mucho tiempo, y no veo por qué debemos rechazarlos o renunciar a ellos. Por el contrario, inuestra actitud debe ser de reclamo permanente, así tengamos que hacer concesiones en cuanto al rótulo que encubra la razón de ser de esa ayuda o de esa cooperación.

Con denuedo, con desesperación, con angustia, debemos encon- 
trar las formas comerciales o no, de obtener para nuestros pueblos la participación aclecuada en la riqueza mundial. Scguramente no hay mana sola forma de lograrlo como lo creen algunos y, por supuesto, esa no es una tarea fácil. Pero éste es un campo en el cual los que trajinamos con el mundo de la politica debenos hacer realidad la concepción de esta noble disciplina y profesión como aquélla cujya tarea es thacer que las cosas que nos parecen imposibles se conviertan en necesarias. 